\title{
Subdivision of metastatic colorectal cancer for identifying patients who benefit more from primary tumor resection
}

\section{Dakui Luo}

Fudan University Shanghai Cancer Center

\section{Zezhi Shan}

Fudan University Shanghai Cancer Center

Qi Liu

Fudan University Shanghai Cancer Center

\section{Sanjun Cai}

Fudan University Shanghai Cancer Center

\section{Qingguo Li}

Fudan University Shanghai Cancer Center

\section{Xinxiang Li ( $\nabla 1149 \mid x x @ s i n a . c o m)$}

Fudan University Shanghai Cancer Center https://orcid.org/0000-0002-5902-3659

\section{Research article}

Keywords: metastatic colorectal cancer, primary tumor resection, survival benefit, SEER

Posted Date: September 8th, 2020

DOl: https://doi.org/10.21203/rs.3.rs-62901/v1

License: (1) This work is licensed under a Creative Commons Attribution 4.0 International License. Read Full License 


\section{Abstract \\ Background}

Stage IV colorectal cancer (CRC) patients are heterogeneous with distinctive clinicopathologic features and prognosis. Radical resection of primary tumor and distant metastases is associated with improved survival outcomes in metastatic CRC. The value of palliative primary tumor resection is controversial. The present study explored which subgroups benefited more from primary tumor resection in metastatic CRC.

\section{Methods}

Between 2004 and 2015, patients with metastatic CRC were identified using the surveillance, epidemiology, and end results (SEER) database. Uni- and multivariable Cox regression analysis were performed to identify factors associated with decreased cancer-specific mortality. The subgroups were divided based on the independent prognostic factors.

\section{Results}

Age, marital status, race, serum CEA, histologic type, differentiation, tumor location, surgery of primary or metastatic lesion, site of metastases, number of metastatic sites, chemotherapy and radiotherapy were identified as independent prognostic factors. Patients with non-white race, normal serum CEA, non-signet ring cell carcinoma, well or moderate differentiation, surgery of metastases, isolated liver metastasis, single metastasis, receiving chemotherapy or radiotherapy presented more survival benefit from primary tumor resection.

\section{Conclusion}

Subgroup of metastatic CRC optimizes decision-making and selected patients will benefit more from primary tumor resection.

\section{Introduction}

Colorectal cancer (CRC) is one of the most common malignant diseases globally[1, 2]. Approximately half of CRC patients developed distant metastases and over $80 \%$ of these patients have unresectable metastases[3-5]. The most common site of involvement is liver that accounted for more than one third of the total population[6].

Patients with a resectable primary and distant metastases could be managed with a staged or simultaneous resection and systemic chemotherapy. Cure is possible for these patients. However, for patients with unresectable metastases, palliative primary tumor resection is only required to manage 
bleeding, obstruction or perforation. The value of palliative primary tumor resection in patients with asymptomatic primary tumors and unresectable metastatic disease is still under debate. A previous study demonstrated that patients with asymptomatic unresectable stage IV colorectal cancer did not benefit from resection of the primary tumor using propensity score matching[7]. Similarly, JCOG1007 study found that primary tumor resection followed by chemotherapy had no benefit over chemotherapy alone for CRC patients with asymptomatic primary tumor and synchronous unresectable metastases [8]. On the contrary, Shida et al revealed that palliative resection of the primary tumor may be associated with improved overall survival. Two large real-world studies also found that palliative primary tumor resection resulted in improved overall and cancer-specific survival $[9,10]$. Besides that, the benefits of palliative resection of the primary tumor appeared to be consistent whether patients received systemic chemotherapy or not [11]. In short, the results seem to be not conclusive enough resulted from inconsistency, and it remains unclear which subgroup of these patients would benefit more from primary tumor resection. In the present study, we performed a large population-based study and subdivided patients with stage IV CRC into different subgroups to identify patients who responded well to primary tumor resection.

\section{Materials And Methods Patients selection}

Patients with metastatic CRC and definite record of primary tumor surgery were identified in the surveillance, epidemiology, and end results (SEER) database (2004-2015). The inclusion criteria were as follows: (1) The site code is 018 (colon) or 130 (rectum); (2) CRC was the only type of primary cancer; (3) information about radiotherapy and survival were available. The following data were documented: age at diagnosis, gender, marital status, race, serum CEA, histologic type, differentiation tumor location, surgery of primary lesion, surgery of metastases, site of metastases, chemotherapy, radiotherapy and survival data.

\section{Statistical analysis}

Uni- and multivariable Cox regression analysis were performed to recognize the prognostic factors. Groups with survival difference were divided into different subgroups. The Cox proportional hazards model was built to estimate the hazard ratios (HR) for cancer-specific mortality after receiving primary tumor resection. All statistical analyses were performed with SPSS 25.0.

\section{Results}

\section{Baseline Characteristics}

A total of 60358 stage IV CRC patients were identified. 34177 patients received primary tumor resection while 26181 patients did not receive primary tumor resection. If the patients with surgery of metastases were excluded, 25126 patients received palliative primary tumor resection while 24750 patients did not 
receive palliative primary tumor resection. The data about site of metastases were only available between 2010-2015. There were 302, 107, 16501, and 1918 patients with isolated bone, brain, liver and lung metastases, respectively. There were 18828, 5720, 707, and 41 patients with single, double, triple, and quadruple metastatic sites, respectively.

\section{Prognostic factors of cancer-specific survival}

Based on univariate analysis, age at diagnosis, gender, marital status, race, serum CEA, histologic type, differentiation tumor location, surgery of primary lesion, surgery of metastases, site of metastases, chemotherapy and radiotherapy affected significantly cancer-specific survival. When these factors were entered a multivariate analysis, it showed that age at diagnosis, marital status, race, serum CEA, histologic type, differentiation tumor location, surgery of primary lesion, surgery of metastases, site of metastases, chemotherapy and radiotherapy were significantly associated with cancer-specific survival (Table 1).

\section{Subgroup of metastatic CRC}

We next divided the patients into different subgroups to evaluate the value of primary tumor resection according to the independent prognostic factors. Univariable Cox regression analysis revealed that patients under 60 years old benefited more from primary tumor resection as compared to those over 60 years old ( $\leq 60$ years old: $\mathrm{HR}, 0.454 ; 95 \% \mathrm{Cl}, 0.440-0.468 ; \mathrm{P}<0.001$, $>60$ years old: $\mathrm{HR}, 0.500 ; 95 \% \mathrm{Cl}, 0.488-$ $0.512, \mathrm{P}<0.001$ ). Besides that, patients with non-white people (white: $\mathrm{HR}, 0.489 ; 95 \% \mathrm{Cl}, 0.478-0.500$; $\mathrm{P}<0.001$, black: HR, $0.447 ; 95 \% \mathrm{Cl}, 0.426-0.469, \mathrm{P}<0.001$ ), normal serum CEA (normal serum CEA: HR, 0.445; 95\% Cl, 0.418-0.473; $\mathrm{P}<0.001$, elevated serum CEA: HR, 0.498; 95\% Cl, 0.485-0.510, $\mathrm{P}<0.001$ ), well or moderate differentiation (well differentiation: $\mathrm{HR}, 0.483 ; 95 \% \mathrm{Cl}, 0.437-0.534 ; \mathrm{P}<0.001$, moderate differentiation: $\mathrm{HR}, 0.482 ; 95 \% \mathrm{Cl}, 0.469-0.496, \mathrm{P}<0.001$, poor differentiation: $\mathrm{HR}, 0.558 ; 95 \% \mathrm{Cl}, 0.535-$ $0.582 ; \mathrm{P}<0.001$, undifferentiated differentiation: $\mathrm{HR}, 0.569 ; 95 \% \mathrm{Cl}, 0.492-0.658,<0.001$ ), surgery of metastases (no surgery: HR, 0.514; $95 \% \mathrm{Cl}, 0.504-0.525 ; \mathrm{P}<0.001$, surgery: $\mathrm{HR}, 0.456 ; 95 \% \mathrm{Cl}, 0.427-0.487$, $P<0.001$ ), isolated liver metastases (lung only: $H R, 0.484 ; 95 \% \mathrm{Cl}, 0.427-0.549 ; P<0.001$, liver only: $H R$, 0.453; $95 \% \mathrm{Cl}, 0.435-0.471, \mathrm{P}<0.001$, brain only: $\mathrm{HR}, 0.717 ; 95 \% \mathrm{Cl}, 0.459-1.120 ; \mathrm{P}=0.144$, bone only: HR, $0.665 ; 95 \% \mathrm{Cl}, 0.491-0.899, \mathrm{P}=0.008$ ), single metastatic site (single site: $\mathrm{HR}, 0.463 ; 95 \% \mathrm{Cl}, 0.446-0.481$; $P<0.001$, double sites: $\mathrm{HR}, 0.643 ; 95 \% \mathrm{Cl}, 0.601-0.688, P<0.001$, triple sites: $\mathrm{HR}, 0.631 ; 95 \% \mathrm{Cl}, 0.512-0.777$; $\mathrm{P}<0.001$, quadruple sites: $\mathrm{HR}, 0.913 ; 95 \% \mathrm{Cl}, 0.376-2.215, \mathrm{P}=0.840$ ), chemotherapy (no chemotherapy or unknown: HR, 0.520; 95\% Cl, 0.505-0.535; $\mathrm{P}<0.001$, chemotherapy: $\mathrm{HR}, 0.457 ; 95 \% \mathrm{Cl}, 0.446-0.469$, $\mathrm{P}<0.001$ ) and radiotherapy (no radiotherapy: $\mathrm{HR}, 0.472 ; 95 \% \mathrm{Cl}, 0.463-0.482 ; \mathrm{P}<0.001$, radiotherapy: $\mathrm{HR}$, $0.414 ; 95 \% \mathrm{Cl}, 0.391-0.438, \mathrm{P}<0.001)$ gained more survival benefits. Of note, patients with signet ring cell carcinoma benefited less from primary tumor resection (adenocarcinoma: $\mathrm{HR}, 0.472 ; 95 \% \mathrm{Cl}, 0.462-0.482$; $\mathrm{P}<0.001$, mucinous adenocarcinoma: $\mathrm{HR}, 0.484 ; 95 \% \mathrm{Cl}, 0.451-0.519, \mathrm{P}<0.001$, signet ring cell carcinoma: $\mathrm{HR}, 0.623 ; 95 \% \mathrm{Cl}, 0.550-0.707 ; \mathrm{P}<0.001)$. No significant difference in survival benefit was observed between patients with different marital status (unmarried: HR, 0.493; 95\% Cl, 0.479-0.507; $\mathrm{P}<0.001$, married: $\mathrm{HR}, 0.476 ; 95 \% \mathrm{Cl}, 0.464-0.490, \mathrm{P}<0.001$ ) or different tumor location (colon: $\mathrm{HR}, 0.436 ; 95 \% \mathrm{Cl}$, 
0.426-0.446; $\mathrm{P}<0.001$, rectum: $\mathrm{HR}, 0.452 ; 95 \% \mathrm{Cl}, 0.435-0.470, \mathrm{P}<0.001)$. Similar results were observed in multivariable Cox regression analysis except for age (Table 2). To evaluate the value of palliative resection of primary tumor, patients who underwent surgery of metastases were excluded from the analysis. Intriguingly, subgroups that benefited more from palliative resection of primary tumor were consistent with those in entire cohort (Table 3).

\section{Discussion}

To date, the value of palliative resection of primary tumor in stage IV CRC patients with unresectable metastases is controversial. It is unreasonable to perform resection of primary tumor for all stage IV CRC patients. Previous studies did explore the subgroups who would gain more survival benefit from palliative resection of primary tumor. Our study focused on which subgroups benefited more from primary tumor resection in metastatic CRC to identify patients who required aggressive therapy. The independent prognostic factors were identified using multivariable Cox regression analysis. Based on these factors, we divided stage IV CRC patients into different subgroups. Our findings indicated that selected patients would gain more survival benefit from primary tumor resection.

Although young CRC patients are apt to have more aggressive characteristics, they have better survival outcomes as compared to elderly patients[12,13]. Our study also found that young stage IV CRC patients had superior prognosis as compared to elderly patients. In the univariable Cox regression analysis, primary tumor resection resulted in $54.6 \%$ and $50 \%$ decreased mortality risk in patients under 60 years old and those over 60 years old. However, the advantage of primary tumor resection in young patients decreased obviously using multivariable Cox regression analysis. It is reasonable to assume that young patients tend to have better performance status and they can tolerate and benefit from more intensive therapy. After adjusting for chemotherapy and radiotherapy, the predictive value of age for primary tumor resection is no longer significant.

Although black patients had poor prognosis as compared to white patients, black patients had $55.8 \%$ decreased mortality risk while white patients had $52 \%$ decreased mortality risk after receiving primary tumor resection. Serum carcinoembryonic antigen (CEA) testing is performed routinely for diagnosis, surveillance and treatment monitoring among CRC patients. Besides that, preoperative serum CEA was an independent prognostic factor in CRC [14] and CEA levels as an indicator could predict pathological complete response after neoadjuvant therapy for rectal cancer[15]. Our study found that serum elevated CEA levels were associated with worse prognosis in metastatic CRC. Primary tumor resection resulted in approximately $55.9 \%$ and $51.9 \%$ reduction in mortality risk for patients with normal and elevated CEA levels. Primary tumor resection is preferred in patients with normal CEA levels. Our previous study also evaluated guiding role of CEA levels in clinical decision-making in stage IIA colon cancer. We found that adjuvant chemotherapy did not acquire substantial survival benefit in patients with elevated pretreatment serum CEA levels[16]. 
Primary colorectal signet-ring cell carcinoma has distinct molecular features[17], aggressive behavior and worse prognosis[18] as compared to other histological subtypes. Our study found that primary tumor resection only decreased $37.7 \%$ mortality risk for patients with signet ring cell carcinoma. Shi et al found that metastatic CRC patients with signet ring cell carcinoma receiving chemotherapy had better survival than patients treated with surgery[19]. The value of primary tumor resection for stage IV CRC patients with signet ring cell type is limited and chemotherapy seems to be more useful for these patients. Similarly, for patients with poor or undifferentiated differentiation, survival benefits conferred by primary tumor resection were less than those with well or moderate differentiation.

Our previous study found that distant metastasis site and the number of metastatic sites were associated with survival of stage IV CRC. Patients with isolated lung metastases presented better prognosis as compared to those with metastases at any other sites[20]. Different metastasis site had distinctive clinicopathological and molecular characteristics. Robinson et al suggested that patients with rectal cancer are more likely than patients with colon cancer to present with synchronous lung metastases[21]. Tie et al. reported that prevalence of KRAS mutations is higher in lung metastases than in liver metastases. It is in question whether different metastasis site affects the therapeutic effect of primary tumor resection[22]. As expected, we found that patients with isolated liver metastases benefited more from primary tumor resection. Although patients with isolated lung metastases had better prognosis than those with isolated liver metastases, patients with isolated lung metastases gained less survival benefit from primary tumor resection than those with isolated liver metastases. In addition, patients with isolated brain metastases did not benefit from primary tumor resection, which may attribute to limited sample size. The number of metastatic sites also had an effect on therapeutic effect of primary tumor resection. Patients with single metastatic site benefited more from primary tumor resection while patients with quadruple metastatic sites did not get benefit from primary tumor resection.

For patients receiving primary tumor resection combined with other therapy, such as surgery of metastases, chemotherapy and radiotherapy, the survival benefits conferred by primary tumor resection were enlarged. Surgery of metastases, chemotherapy and radiotherapy had a synergistic effect on primary tumor resection. For patients who can tolerate the intensive therapy, combination therapy will benefit selected patients. Similarly, for patients with unresectable metastases, palliative primary tumor resection was associated with more survival benefit in patients who received chemotherapy or radiotherapy.

Inevitably, our study has several limitations. Firstly, some prognostic variables were missing in SEER database, such as perineural invasion, vascular invasion, chemotherapy regimens, response to chemotherapy and other metastatic sites, making it impossible to adjust for other potential confounders. Secondly, the sample size in some subgroups is insufficient. Thirdly, it is hard to acquire progression-free survival, which is critical for evaluation of therapeutic effect in stage IV disease.

In conclusion, the subdivision of metastatic CRC contributes to maximization of the value of primary tumor resection and facilitates individualized treatment options. 


\section{Declarations}

\section{Ethics approval and consent to participate}

This study was carried out based on SEER database which is publicly accessible. We have acquired permit from official mission for the research purpose. No personal identifying information was reflected. The informed consent was not required for our study.

\section{Consent for publication}

Yes.

\section{Competing interests}

We declare no conflicts of interest.

\section{Funding}

This work was supported by the National Natural Science Foundation of China (Grant NO. 81772599; NO. 81972260; NO. 81702353) and Shanghai Municipal Natural Science Foundation (17ZR1406400). The funders had no role in the study design, data collection, and analysis, decision to publish, or preparation of the manuscript.

\section{Consent to participate}

Yes.

\section{Authors' contributions}

$\mathrm{XL}$ and QL conceived this study. DL and QL improved the study design and contributed to the interpretation of results. ZS collected the data. SC performed data processing and statistical analysis. DL and ZS wrote the manuscript. QL revised the manuscript. All authors approved the final version.

\section{Acknowledgements}

We acknowledged the efforts of the Surveillance, Epidemiology, and End Results (SEER) Program tumor registries in the creation of SEER database.

\section{Data Availability Statement}

The datasets are available in the SEER repository and can be obtained from https://seer.cancer.gov.

\section{References}


1. Bray F, Ferlay J, Soerjomataram I, Siegel RL, Torre LA, Jemal A. Global cancer statistics 2018 : GLOBOCAN estimates of incidence and mortality worldwide for 36 cancers in 185 countries. CA Cancer J Clin. 2018;68(6):394-424. doi:10.3322/caac.21492.

2. Siegel RL, Miller KD, Fedewa SA, Ahnen DJ, Meester RGS, Barzi A, et al. Colorectal cancer statistics, 2017. CA Cancer J Clin. 2017;67(3):177-93. doi:10.3322/caac.21395.

3. Van Cutsem E, Nordlinger B, Adam R, Kohne CH, Pozzo C, Poston G, et al. Towards a pan-European consensus on the treatment of patients with colorectal liver metastases. Eur $\mathrm{J}$ Cancer. 2006;42(14):2212-21. doi:10.1016/j.ejca.2006.04.012.

4. Muratore A, Zorzi D, Bouzari H, Amisano M, Massucco P, Sperti E, et al. Asymptomatic colorectal cancer with un-resectable liver metastases: immediate colorectal resection or up-front systemic chemotherapy? Ann Surg Oncol. 2007;14(2):766-70. doi:10.1245/s10434-006-9146-1.

5. Tsai MS, Su YH, Ho MC, Liang JT, Chen TP, Lai HS, et al. Clinicopathological features and prognosis in resectable synchronous and metachronous colorectal liver metastasis. Ann Surg Oncol. 2007;14(2):786-94. doi:10.1245/s10434-006-9215-5.

6. Kemeny N. Management of liver metastases from colorectal cancer. Oncology (Williston Park). 2006;20(10):1161-76. 79; discussion 79-80, 85 - 6 .

7. Yun JA, Huh JW, Park YA, Cho YB, Yun SH, Kim HC, et al. The role of palliative resection for asymptomatic primary tumor in patients with unresectable stage IV colorectal cancer. Dis Colon Rectum. 2014;57(9):1049-58. doi:10.1097/DCR.0000000000000193.

8. Moritani K, Kanemitsu Y, Shida D, Shitara K, Mizusawa J, Katayama H, et al. A randomized controlled trial comparing primary tumour resection plus chemotherapy with chemotherapy alone in incurable stage IV colorectal cancer: JCOG1007 (iPACS study). Jpn J Clin Oncol. 2020;50(1):89-93. doi:10.1093/jjco/hyz173.

9. Maroney S, de Paz CC, Reeves ME, Garberoglio C, Raskin E, Senthil M, et al. Benefit of Surgical Resection of the Primary Tumor in Patients Undergoing Chemotherapy for Stage IV Colorectal Cancer with Unresected Metastasis. J Gastrointest Surg. 2018;22(3):460-6. doi:10.1007/s11605-017-36175.

10. Tarantino I, Warschkow R, Worni M, Cerny T, Ulrich A, Schmied BM, et al. Prognostic Relevance of Palliative Primary Tumor Removal in 37,793 Metastatic Colorectal Cancer Patients: A PopulationBased, Propensity Score-Adjusted Trend Analysis. Ann Surg. 2015;262(1):112-20. doi:10.1097/SLA.0000000000000860.

11. Gresham G, Renouf DJ, Chan M, Kennecke HF, Lim HJ, Brown C, et al. Association between palliative resection of the primary tumor and overall survival in a population-based cohort of metastatic colorectal cancer patients. Ann Surg Oncol. 2014;21(12):3917-23. doi:10.1245/s10434-014-3797-0.

12. Inra JA, Syngal S. Colorectal cancer in young adults. Dig Dis Sci. 2015;60(3):722-33. doi:10.1007/s10620-014-3464-0.

13. Campos FG. Colorectal cancer in young adults: A difficult challenge. World J Gastroenterol. 2017;23(28):5041-4. doi:10.3748/wjg.v23.i28.5041. 
14. Becerra AZ, Probst CP, Tejani MA, Aquina CT, Gonzalez MG, Hensley BJ, et al. Evaluating the Prognostic Role of Elevated Preoperative Carcinoembryonic Antigen Levels in Colon Cancer Patients: Results from the National Cancer Database. Ann Surg Oncol. 2016;23(5):1554-61. doi:10.1245/s10434-015-5014-1.

15. Wallin U, Rothenberger D, Lowry A, Luepker R, Mellgren A. CEA - a predictor for pathologic complete response after neoadjuvant therapy for rectal cancer. Dis Colon Rectum. 2013;56(7):859-68. doi:10.1097/DCR.0b013e31828e5a72.

16. Liu Q, Huang Y, Luo D, Zhang S, Cai S, Li Q, et al. Evaluating the Guiding Role of Elevated Pretreatment Serum Carcinoembryonic Antigen Levels for Adjuvant Chemotherapy in Stage IIA Colon Cancer: A Large Population-Based and Propensity Score-Matched Study. Front Oncol. 2019;9:37. doi:10.3389/fonc.2019.00037.

17. Korphaisarn K, Morris V, Davis JS, Overman MJ, Fogelman DR, Kee BK, et al. Signet ring cell colorectal cancer: genomic insights into a rare subpopulation of colorectal adenocarcinoma. $\mathrm{Br} J$ Cancer. 2019;121(6):505-10. doi:10.1038/s41416-019-0548-9.

18. Liang Z, Yan D, Li G, Cheng H. Clinical Analysis of Primary Colorectal Signet-Ring Cell Carcinoma. Clin Colorectal Cancer. 2018;17(1):e39-44. doi:10.1016/j.clcc.2017.06.010.

19. Shi T, Huang M, Han D, Tang $X$, Chen Y, Li Z, et al. Chemotherapy is associated with increased survival from colorectal signet ring cell carcinoma with distant metastasis: A Surveillance, Epidemiology, and End Results database analysis. Cancer Med. 2019;8(4):1930-40. doi:10.1002/cam4.2054.

20. Luo D, Liu Q, Yu W, Ma Y, Zhu J, Lian P, et al. Prognostic value of distant metastasis sites and surgery in stage IV colorectal cancer: a population-based study. Int J Colorectal Dis. 2018;33(9):1241-9. doi:10.1007/s00384-018-3091-x.

21. Robinson JR, Newcomb PA, Hardikar S, Cohen SA, Phipps Al. Stage IV colorectal cancer primary site and patterns of distant metastasis. Cancer Epidemiol. 2017;48:92-5. doi:10.1016/j.canep.2017.04.003.

22. Tie J, Lipton L, Desai J, Gibbs P, Jorissen RN, Christie M, et al. KRAS mutation is associated with lung metastasis in patients with curatively resected colorectal cancer. Clin Cancer Res. 2011;17(5):112230. doi:10.1158/1078-0432.CCR-10-1720.

\section{Tables}

Table 1 Univariate and multivariate analysis for cancer-specific survival in metastatic colorectal cancer. 
Variable

Reference

$>60$

$\begin{array}{ll}1.558 & <0.001 \\ (1.528- & 1.320) \\ 1.587) & \end{array}$

\section{Sex}

Male

Reference

Female

$\begin{array}{ll}1.044 & <0.001 \\ (1.025- & 1.007) \\ 1.063) & \end{array}$

\section{Marital status}

Unmarried

Reference

Married
0.776
$(0.761-$
0.790 )
$<0.001$
0.905)

Unknown

\section{Race}

White

Reference

Black

$\begin{array}{ll}1.100 & <0.001 \\ (1.072- & 1.080) \\ 1.129) & \end{array}$

Others

$\begin{array}{ll}0.888 & <0.001 \\ (0.859- & 0.931) \\ 0.918) & \end{array}$

\section{Serum CEA}

Normal

Reference

Reference

Elevated

$\begin{array}{ll}1.505 & <0.001 \\ (1.459- & 1.515) \\ 1.553) & \end{array}$

\section{Reference}

Reference

\section{Multivariate analysis}

$\mathrm{HR}(95 \% \mathrm{Cl}) \quad P$ value

\section{Reference}

$$
0.988(0.970-\quad 0.214
$$

$$
0.888(0.870-\quad<0.001
$$

$$
1.052(1.025-\quad<0.001
$$

$0.900(0.870-\quad<0.001$




\section{Histologic type}

Adenocarcinoma

Reference

Mucinous

adenocarcinoma

1.070

(1.035-

1.106)
Signet ring cell

carcinoma

1.578

(1.482-

1.679)

Others

$\begin{array}{ll}1.709 & <0.001 \\ (1.635- & 1.376) \\ 1.785) & \end{array}$

Reference

$$
<0.001
$$

1.138)

$1.101(1.064-\quad<0.001$

$1.349(1.266-\quad<0.001$

$1.316(1.257-\quad<0.001$

\section{Differentiation}

Well

Reference

Reference

\begin{tabular}{|c|c|c|c|}
\hline Moderate & $\begin{array}{l}0.956 \\
(0.909- \\
1.005)\end{array}$ & $\begin{array}{l}0.080 \\
1.139)\end{array}$ & 1.083 (1.030- \\
\hline
\end{tabular}

Poor

1.433

(1.361-

1.510)

Undifferentiated

1.453

(1.349-

1.564)

$$
<0.001
$$

1.722)

$1.634(1.550-$

$<0.001$

Unknown

I

$<0.001$

1.954)

1.814 (1.683-

$<0.001$

\section{Tumor location}

Colon

Reference

Reference

Rectum

$\begin{array}{ll}0.819 & <0.001 \\ (0.802- & 0.816) \\ 0.836) & \end{array}$

0.797 (0.779-

$<0.001$

\section{Surgery of} primary lesion

No

Yes

Reference

$\begin{array}{llll}0.479 & <0.001 & 0.475(0.464- & <0.001 \\ (0.470- & 0.486) & & \\ 0.488) & & \end{array}$

Reference

\section{Surgery of}

metastases

No
Reference

Page $11 / 23$ 
Reference

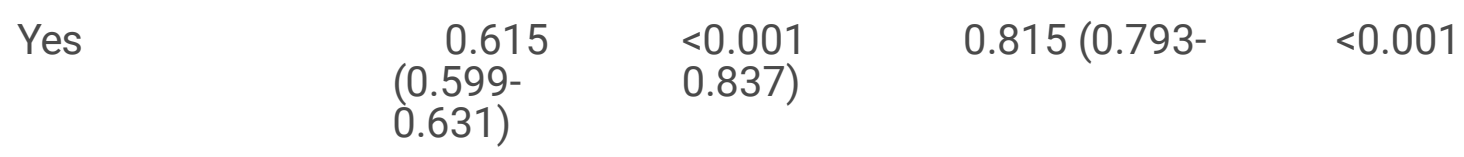

Unknown

I

I

\section{Site of}

metastases

Lung only

Reference

Reference

Liver only

$\begin{array}{ll}1.240 & <0.001 \\ (1.163- & 1.464) \\ 1.322) & \end{array}$

Brain only

2.116

(1.683-

2.660)

Bone only

1.909

(1.643-

2.218)

Multiple

1.988

$<0.001$

2.685)

$2.130(1.690-$

$<0.001$

(1.858-

2.127)

\section{Number of}

metastatic sites

Single

Reference

Reference

Double

$\begin{array}{ll}1.557 & <0.001 \\ (1.502- & 1.934) \\ 1.614) & \end{array}$

Triple

2.247
$(2.066-$
$2.445)$

Quadruple

$\begin{array}{ll}3.271 & <0.001 \\ (2.358- & 6.206) \\ 4.538) & \end{array}$

4.443 (3.181-

$<0.001$

\section{Chemotherapy}

No/Unknown

Reference

Reference

Yes

0.393

(0.386-

0.401 )

$2.452(2.210-\quad<0.001$

$<0.001$
$2.720)$

$1.805(1.684-\quad<0.001$

$\begin{array}{lllll}\text { Yes } & \text { Reference } & & \\ & 0.393 & <0.001 & 0.421(0.413- & <0.001 \\ & (0.386- & 0.430) & & \\ 0.401) & & & \end{array}$

\section{Radiotherapy}




\begin{tabular}{|lcccc|} 
No & \multicolumn{3}{c|}{ Reference } & \\
\hline Yes & $\begin{array}{l}0.728 \\
(0.708-\end{array}$ & $<0.001$ & $0.927(0.898-$ & $<0.001$ \\
& $0.750)$ & & & \\
Unknown & $/$ & & $/$ \\
\hline
\end{tabular}

Table 2 Univariate and multivariate analysis of cancer-specific mortality for patients with or without primary tumor resection. 
Variable

Reference

Age

$\leq 60$

$\begin{array}{llll}0.454 & <0.001 & 0.464(0.448- & <0.001 \\ (0.440- & 0.481) & & \\ 0.468) & & \end{array}$

$>60$

Reference

$\begin{array}{llll}0.500 & <0.001 & 0.483(0.469- & <0.001 \\ (0.488- & 0.498) & & \\ 0.512) & & \end{array}$

\section{Marital status}

Unmarried

Reference

Reference

$\begin{array}{llll}0.493 & <0.001 & 0.484(0.468- & <0.001 \\ (0.479- & 0.501) & & \\ 0.507) & & & \end{array}$

Married

Reference

Reference

$\begin{array}{llll}0.476 & <0.001 & 0.467(0.453- & <0.001 \\ (0.464- & 0.483) & & \\ 0.490) & & \end{array}$

\section{Race}

White

Reference

Reference

$\begin{array}{lll}0.489 & <0.001 & 0.480(0.468- \\ (0.478- & 0.493 & \\ 0.500) & & \end{array}$

Black

\section{Reference}

Reference

$\begin{array}{llll}0.447 & <0.001 & 0.442(0.417- & <0.001 \\ (0.426- & 0.468) & & \\ 0.469) & & \end{array}$

Others

Reference

Reference

$\begin{array}{llll}0.447 & <0.001 & 0.480(0.444- & <0.001 \\ \left(0.418^{-}\right. & 0.519) & & \end{array}$


Serum CEA

Normal

Reference

$\begin{array}{llll}0.445 & <0.001 & 0.441(0.410- & <0.001 \\ (0.418- & 0.475) & & \\ 0.473) & & \end{array}$

Elevated

Reference

$\begin{array}{llll}0.498 & <0.001 & 0.481(0.467- & <0.001 \\ (0.485- & 0.496) & & \\ 0.510) & & \end{array}$

Histologic type

Adenocarcinoma

Reference

Reference

$\begin{array}{llll}0.472 & <0.001 & 0.468(0.457- & <0.001 \\ (0.462- & 0.480) & & \\ 0.482) & & \end{array}$

Reference

Reference

Mucinous

adenocarcinoma

0.484

$(0.451-$

$0.519)$

Reference

Signet ring cell carcinoma
0.623
(0.550-
$0.707)$

Reference

Others

$\begin{array}{ll}0.575 & <0.001 \\ (0.525- & 0.590) \\ 0.629) & \end{array}$

Reference

$<0.001$

$0.496)$

$0.453(0.414-\quad<0.001$ 


$\begin{array}{llll}0.482 & <0.001 & 0.450(0.436- & <0.001 \\ (0.469- & 0.464) & & \\ 0.496) & & \end{array}$

Poor

Reference

Reference

$\begin{array}{llll}0.558 & <0.001 & 0.529(0.505- & <0.001 \\ (0.535- & 0.554) & & \\ 0.582) & & \end{array}$

Undifferentiated

Reference

Reference

$\begin{array}{llll}0.569 & <0.001 & 0.570(0.486- & <0.001 \\ (0.492- & 0.668) & & \\ 0.658) & & \end{array}$

\section{Tumor location}

Colon

Reference

Reference

$\begin{array}{llll}0.436 & <0.001 & 0.472(0.459- & <0.001 \\ (0.426- & 0.485) & & \\ 0.446) & & \end{array}$

Rectum

$\begin{array}{ll}\text { Reference } & \\ 0.452 & <0.001 \\ (0.435- & 0.511) \\ 0.470) & \end{array}$

Reference

\section{Surgery of}

metastases

No

Reference

Reference

$\begin{array}{llll}0.514 & <0.001 & 0.480(0.469- & <0.001 \\ (0.504- & 0.492) & & \\ 0.525) & & & \end{array}$

Yes

Reference

$\begin{array}{llll}0.456 & <0.001 & 0.448(0.415- & <0.001 \\ (0.427- & 0.485) & & \\ 0.487) & & \end{array}$

\section{Site of}

metastases

Lung only

Reference

Reference

$\begin{array}{llll}0.484 & <0.001 & 0.466(0.401- & <0.001 \\ (0.427- & 0.542) & & \end{array}$


Liver only

\begin{tabular}{llll}
\multicolumn{1}{l}{ Reference } & & & \\
0.453 & $<0.001$ & $0.471(0.449-$ & $<0.001$ \\
$(0.435-$ & $0.495)$ & & \\
$0.471)$ & & & \\
\hline
\end{tabular}

Brain only

$\begin{array}{llll}\text { Reference } & & & \\ 0.717 & 0.144 & 0.649(0.385- & <0.001 \\ (0.459- & 1.096) & & \\ 1.120) & & & \end{array}$

Bone only

$\begin{array}{llll}\text { Reference } & & & \\ 0.665 & 0.008 & 0.499(0.353- & <0.001 \\ 0.491- & 0.704) & & \\ .899) & & & \end{array}$

Multiple

Reference

$\begin{array}{llll}0.634 & <0.001 & 0.596(0.554- & <0.001 \\ (0.595- & 0.642) & & \\ 0.676) & & \end{array}$

Number of

metastatic sites

Single

Reference

Reference

$\begin{array}{llll}0.463 & <0.001 & 0.471(0.450- & <0.001 \\ (0.446- & 0.493) & & \\ 0.481) & & \end{array}$

Double

Reference

Reference

$\begin{array}{llll}0.643 & <0.001 & 0.598(0.553- & <0.001 \\ (0.601- & 0.646) & & \\ 0.688) & & \end{array}$

Triple

Reference

Reference

$\begin{array}{llll}0.631 & <0.001 & 0.563(0.448- & <0.001 \\ (0.512- & 0.708) & & \\ 0.777) & & \end{array}$

Quadruple

Reference

Reference

$\begin{array}{cccc}0.913 & 0.840 & 0.707(0.215- & 0.569 \\ (0.376- & 2.327) & & \end{array}$


Chemotherapy

No/Unknown

Reference

Reference

$\begin{array}{llll}0.520 & <0.001 & 0.522(0.503- & <0.001 \\ (0.505- & 0.541) & & \\ 0.535) & & \end{array}$

Yes

Reference

Reference

$\begin{array}{llll}0.457 & <0.001 & 0.464(0.450- & <0.001 \\ (0.446- & 0.477) & & \\ 0.469) & & \end{array}$

\section{Radiotherapy}

No

Reference

Reference

$\begin{array}{lll}0.472 & <0.001 & 0.480(0.469- \\ (0.463- & 0.492) & \\ 0.482) & & \end{array}$

Yes

Reference

Reference

$\begin{array}{llll}0.414 & <0.001 & 0.443(0.416- & <0.001 \\ 0.391- & 0.472) & & \\ 0.438) & & \end{array}$

Table 3 Univariate and multivariate analysis of cancer-specific mortality for patients with or without palliative primary tumor resection. 
Variable

Reference

Age

$\leq 60$

$\begin{array}{ll}0.454 & <0.001 \\ (0.440- & 0.481) \\ 0.468) & \end{array}$

$>60$

Reference

$\begin{array}{llll}0.500 & <0.001 & 0.483(0.469- & <0.001 \\ (0.488- & 0.498) & & \\ 0.512) & & \end{array}$

Reference

$$
0.464(0.448-\quad<0.001
$$

$\begin{array}{llll}\mathrm{HR}(95 \% \mathrm{Cl}) & P & \mathrm{HR}(95 \% \mathrm{Cl}) & P \text { value } \\ \text { value } & \end{array}$

Multivariate analysis

Univariate analysis
$.481)$

0.468)

\section{Marital status}

Unmarried

Reference

$\begin{array}{ll}0.493 & <0.001 \\ (0.479- & 0.501) \\ 0.507) & \end{array}$

Married

Reference

$\begin{array}{llll}0.476 & <0.001 & 0.467(0.453- & <0.001 \\ (0.464- & 0.483) & & \\ 0.490) & & \end{array}$

\section{Race}

White

$$
\text { Reference }
$$

$\begin{array}{lll}0.489 & <0.001 & 0.480(0.468- \\ (0.478- & 0.493 & \\ 0.500) & & \end{array}$

Black

\section{Reference}

$\begin{array}{llll}0.447 & <0.001 & 0.442(0.417- & <0.001 \\ (0.426- & 0.468) & & \\ 0.469) & & \end{array}$

Others

Reference

Reference

$\begin{array}{cccc}0.447 & <0.001 & 0.480(0.444- & <0.001 \\ (0.418- & 0.519) & & \end{array}$




\section{Serum CEA}

Normal

Reference

$\begin{array}{llll}0.445 & <0.001 & 0.441(0.410- & <0.001 \\ (0.418- & 0.475) & & \\ 0.473) & & \end{array}$

Elevated

Reference

$\begin{array}{llll}0.498 & <0.001 & 0.481(0.467- & <0.001 \\ (0.485- & 0.496) & & \\ 0.510) & & & \end{array}$

\section{Histologic type}

Adenocarcinoma

Reference

\section{Reference}

$\begin{array}{llll}0.472 & <0.001 & 0.468(0.457- & <0.001 \\ (0.462- & 0.480) & & \\ 0.482) & & \end{array}$

Reference

Reference

Mucinous

adenocarcinoma

0.484

(0.451-

$0.519)$

$<0.001$

0.496 )

$0.453(0.414-\quad<0.001$

Reference

Reference

Signet ring cell carcinoma

$\begin{array}{ll}0.623 & <0.001 \\ (0.550- & 0.762) \\ 0.707) & \end{array}$

Reference

\section{Reference}

Others

$\begin{array}{ll}0.575 & <0.001 \\ (0.525- & 0.590) \\ 0.629) & \end{array}$

\section{Differentiation}

Well

Reference

Reference

$\begin{array}{llll}0.483 & <0.001 & 0.442(0.395- & <0.001 \\ (0.437- & 0.495) & & \\ 0.534) & & \end{array}$

Moderate

Reference 


\begin{tabular}{|c|c|c|c|c|}
\hline & $\begin{array}{l}0.482 \\
(0.469- \\
0.496)\end{array}$ & $\begin{array}{l}<0.001 \\
0.464)\end{array}$ & 0.450 (0.436- & $<0.001$ \\
\hline \multirow[t]{2}{*}{ Poor } & Reference & & Reference & \\
\hline & $\begin{array}{l}\quad 0.558 \\
(0.535- \\
0.582)\end{array}$ & $\begin{array}{l}<0.001 \\
0.554)\end{array}$ & $0.529(0.505-$ & $<0.001$ \\
\hline \multirow[t]{2}{*}{ Undifferentiated } & Reference & & Reference & \\
\hline & $\begin{array}{l}0.569 \\
(0.492- \\
0.658)\end{array}$ & $\begin{array}{l}<0.001 \\
0.668)\end{array}$ & $0.570(0.486-$ & $<0.001$ \\
\hline \multicolumn{5}{|l|}{ Tumor location } \\
\hline \multirow[t]{2}{*}{ Colon } & Reference & & Reference & \\
\hline & $\begin{array}{l}\quad 0.467 \\
(0.456- \\
0.479)\end{array}$ & $\begin{array}{l}<0.001 \\
0.485)\end{array}$ & 0.472 (0.459- & $<0.001$ \\
\hline \multirow[t]{2}{*}{ Rectum } & Reference & & Reference & \\
\hline & $\begin{array}{l}0.492 \\
(0.472- \\
0.513)\end{array}$ & $\begin{array}{l}<0.001 \\
0.511)\end{array}$ & $0.490(0.471-$ & $<0.001$ \\
\hline \multicolumn{5}{|l|}{$\begin{array}{l}\text { Site of } \\
\text { metastases }\end{array}$} \\
\hline \multirow[t]{2}{*}{ Lung only } & Reference & & Reference & \\
\hline & $\begin{array}{l}0.484 \\
(0.427- \\
0.549)\end{array}$ & $\begin{array}{l}<0.001 \\
0.542)\end{array}$ & $0.466(0.401-$ & $<0.001$ \\
\hline \multirow[t]{2}{*}{ Liver only } & Reference & & & \\
\hline & $\begin{array}{l}\quad 0.453 \\
(0.435- \\
0.471)\end{array}$ & $\begin{array}{l}<0.001 \\
0.495)\end{array}$ & 0.471 (0.449- & $<0.001$ \\
\hline \multirow[t]{2}{*}{ Brain only } & Reference & & & \\
\hline & $\begin{array}{l}\quad 0.717 \\
(0.459- \\
1.120)\end{array}$ & $\begin{array}{l}0.144 \\
1.096)\end{array}$ & 0.649 (0.385- & $<0.001$ \\
\hline
\end{tabular}


Bone only

Reference

$\begin{array}{llll}0.665 & 0.008 & 0.499(0.353- & <0.001 \\ (0.491- & 0.704) & & \\ 0.899) & & \end{array}$

Multiple

Reference

\begin{tabular}{llll}
\multicolumn{1}{c}{0.634} & $<0.001$ & $0.596(0.554-$ & $<0.001$ \\
$(0.595-$ & $0.642)$ & & \\
$0.676)$ & &
\end{tabular}

Number of metastatic sites

Single

Reference

Reference

$\begin{array}{llll}0.463 & <0.001 & 0.471(0.450- & <0.001 \\ (0.446- & 0.493) & & \\ 0.481) & & \end{array}$

Double

Reference

Reference

$\begin{array}{llll}0.643 & <0.001 & 0.598(0.553- & <0.001 \\ (0.601- & 0.646) & & \\ 0.688) & & & \end{array}$

Triple

Reference

Reference

$\begin{array}{llll}0.631 & <0.001 & 0.563(0.448- & <0.001 \\ (0.512- & 0.708) & & \\ 0.777) & & \end{array}$

Quadruple

Reference

$$
\text { Reference }
$$

$\begin{array}{llll}0.913 & 0.840 & 0.707(0.215- & 0.569 \\ (0.376- & 2.327) & & \\ 2.215) & & & \end{array}$

\section{Chemotherapy}

No/Unknown

Reference

Reference

$\begin{array}{llll}0.520 & <0.001 & 0.522(0.503- & <0.001 \\ (0.505- & 0.541) & & \\ 0.535) & & \end{array}$

Yes

Reference

Reference

$\begin{array}{llll}0.457 & <0.001 & 0.464(0.450- & <0.001 \\ (0.446- & 0.477) & \end{array}$


0.469)

Radiotherapy

No

\begin{tabular}{|c|c|c|}
\hline Reference & & Reference \\
\hline $\begin{array}{l}0.472 \\
(0.463- \\
0.482)\end{array}$ & $\begin{array}{l}<0.001 \\
0.492)\end{array}$ & $0.480(0.469-$ \\
\hline
\end{tabular}

Yes

Reference

Reference

$0.414<0.001 \quad 0.443(0.416-\quad<0.001$

(0.391-

0.472)

0.438) 